\title{
Somatic recombination may explain linear psoriasis
}

\author{
Rudolf Happle
}

Linear psoriasis is an uncommon skin disease of so far unknown origin. ${ }^{1}$ Although many cases reported in the past under this diagnosis should today be reclassified as examples of inflammatory linear verrucous epidermal naevus, ${ }^{2}$ or as psoriasis superimposing an epidermal naevus, ${ }^{3}$ there still remain a number of observations that undoubtedly represent true linear psoriasis. $^{145}$

To explain this unusual phenomenon, the following concept is proposed. Psoriasis vulgaris is considered to be a polygenic disorder. ${ }^{6} \mathrm{~A}$ subject affected with linear psoriasis is similarly heterozygous for several genes predisposing to psoriasis vulgaris. During early embryogenesis, crossing over would occur in a somatic cell, resulting in exchange of a segment harbouring one of the predisposing genes. (Evidence for somatic crossing over has been provided in animals and plants, ${ }^{78}$ and it seems reasonable to assume that similar events occur in human cells at all stages of life. ${ }^{10}$ ) In this way, one of the daughter cells may become homozygous for a psoriasis gene, and this would be the stem cell of a clone proliferating in a linear pattern during embryonic development of the skin. " For the ultimate manifestation of linear psoriasis, the presence of other predisposing genes as well as environmental factors would be necessary. This would explain why linear psoriasis is mostly absent at birth but develops later in life. In other words, an ordinary additive gene predisposing in the heterozygous state to psoriasis vulgaris would act in the homozygous state, owing to somatic recombination, as a major gene predisposing to linear psoriasis.

Alternative somatic mutational events resulting in homozygosity for this allele would be mitotic non-

Department of Dermatology, University of Nijmegen, PO Box 9101, NL-6500 HB Nijmegen, The Netherlands. R Happle

Received for publication 16 October 1990.

Accepted for publication 23 October 1990. disjunction with loss of a chromosome and reduplication of the homologous counterpart, gene conversion, or a point mutation involving the locus. ${ }^{9}$ These mechanisms, however, appear to be less likely to explain linear psoriasis when compared to the simple event of somatic recombination.

The proposed concept offers a plausible explanation for the following features characteristic of linear psoriasis: (1) it is a non-hereditary trait; (2) the linear distribution corresponds to a pattern observed in many other mosaic skin disorders ${ }^{11}$; (3) patients suffering from linear psoriasis may be affected, in addition, with common psoriasis in the form of bilateral non-linear lesions ${ }^{4}{ }^{5} ;(4)$ the lesions of linear psoriasis tend to be more pronounced than those of the associated psoriasis vulgaris. ${ }^{5}$

If this hypothesis holds true, linear psoriasis would constitute a unique experiment of nature that may help to elucidate further the polygenic basis of psoriasis.

1 Atherton DJ, Kahana M, Russell-Jones R. Naevoid psoriasis. $\mathrm{Br}$ f Dermatol 1989;120:837-41.

2 Morag C, Metzker A. Inflammatory linear verrucous epidermal nevus: report of seven new cases and review of the literature. Pediatr Dermatol 1985;3:15-18.

3 Bondi EE. Psoriasis overlying an epidermal nevus. Arch Dermatol 1979;115:624-5.

4 Beek CH, Jantzen J. On acute linear dermatoses. Acta Dermatovenereol (Stockh) 1955;35:319-26.

5 Leslie G. Linear psoriasis. Br $\mathcal{F}$ Dermatol 1951;63:262-3.

6 Watson W, Cann HM, Farber EM, Nall ML. The genetics of psoriasis. Arch Dermatol 1972;105:197-207.

7 Graf U, Würgler FE, Katz AJ, et al. Somatic mutation and recombination test in Drosophila melanogaster. Environ Mutagen 1984;6:153-88.

8 Carlson PS. Mitotic crossing-over in a higher plant. Genet Res 1974;24:109-12.

9 Cavenee WK, Dryja TP, Phillips RA, et al. Expression of recessive alleles by chromosomal mechanisms in retinoblastoma.
Nature 1983;305:779-84.

10 Langlois RG, Bigbee WL, Jensen RH, German J. Evidence for increased in vivo mutation and somatic recombination in Bloom's syndrome. Proc Natl Acad Sci USA 1989;86:670-4. 11 Happle R. Lyonization and the lines of Blaschko. Hum Genet
1985;70:200-6. 